\title{
The Enrichment and Transfer of Heavy Metals for Two Ferns in Pb-Zn Tailing
}

\author{
Jiajie Mai ${ }^{a}$, Qihe Yang ${ }^{b}$, Yingfei Zhang ${ }^{c}$, Xianlu Zeng ${ }^{d}$, Yanmei Zhong ${ }^{e}$ and Deliang Liu ${ }^{\mathrm{f}}$ \\ School of Life Science, Jiaying University, Meizhou 514015, China

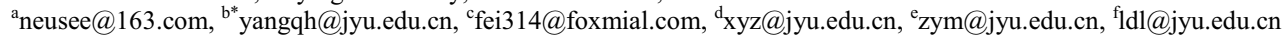

\begin{abstract}
The enrichment and transfer of 8 heavy metals of Equisetum ramosissimum and Pteris vittata growing naturally close to edge of the sewage pool in Bencun $\mathrm{Pb}-\mathrm{Zn}$ Tailing, Eastern Guangdong were investigated. The results indicated that the pollution of $\mathrm{Cd}, \mathrm{Pb}, \mathrm{Hg}, \mathrm{Zn}$ was very severe in this tailing, followed by $\mathrm{Cu}$ and $\mathrm{Mn}$. The potential ecological risk of heavy metals was assessed to be very strong based on soil background values of Guangdong Province and at high risk according to criteria of the second grade State Soil Environmental Quality Standard, and $\mathrm{Cd}, \mathrm{Hg}, \mathrm{Pb}$ were the main factors leading to potential ecological risk. The content of 8 heavy metals in the two ferns did not reach critical content of hyperaccumulator, so neither of them was typical hyperaccumulator, but both had a certain tolerance to these heavy metal pollution. Underground parts of Pteris vittata had an enrichment coefficient above 1 and that of Equisetum ramosissimum had a value near 1, therefore the two ferns could be utilized as potential enrichment plants. The two ferns have strong adaptability to the tailing habitat and can be used as pioneers in ecological restoration of $\mathrm{Pb}-\mathrm{Zn}$ tailings.
\end{abstract}

Keywords. Equisetum ramosissimum, Pteris vittata, heavy metal phytoremediation

\section{Introduction}

The enrichment and transfer of 8 heavy metals of Equisetum ramosissimum and Pteris vittata growing naturally close to edge of the sewage pool in Bencun Pb-Zn Tailing, Eastern Guangdong were investigated. The results indicated that the pollution of $\mathrm{Cd}, \mathrm{Pb}, \mathrm{Hg}, \mathrm{Zn}$ was very severe in this tailing, followed by $\mathrm{Cu}$ and $\mathrm{Mn}$. The potential ecological risk of heavy metals was assessed to be very strong based on soil background values of Guangdong Province and at high risk according to criteria of the second grade State Soil Environmental Quality Standard [1], and $\mathrm{Cd}, \mathrm{Hg}, \mathrm{Pb}$ were the main factors leading to potential ecological risk. The content of 8 heavy metals in the two ferns did not reach critical content of hyperaccumulator, so neither of them was typical hyperaccumulator, but both had a certain tolerance to these heavy metal pollution. Underground parts of Pteris vittata had an enrichment coefficient above 1 and that of Equisetum ramosissimum had a value near 1 , therefore the two ferns could be utilized as potential enrichment plants. The two ferns have strong adaptability to the tailing habitat and can be used as pioneers in ecological restoration of $\mathrm{Pb}-\mathrm{Zn}$ tailings. Soil resource is one of the main sources of livelihood and the basis of terrestrial ecosystem and agricultural development. It has important significance to maintain the species diversity and determine the yield and quality of agriculture. The heavy metal pollution in soil is a kind of irreversible pollution process and also a severe threat to human, which directly leads to crop production and brings serious damage to human health through a negative feedback effect. In mine tailings, such as $\mathrm{Pb}-\mathrm{Zn}$ tailings, their components and residual flotation reagent bring about serious contamination to ecological environment. The acidic water produced by sulfide in tailings caused the leaching of heavy metals to contaminate the soil and water environment in tailing area.

Bencun Pb-Zn Mine Tailing (24o22'54"E, 116o13'12"N), with a slope of 15o 20o (Figure 1), is one of mine tailings with the most largest volume of industrial solid waste in Meizhou City, East Guangdong, South China. The mine started operation in 1970 and abandoned in 1980. The mineral waste residue had been directly discharged and piled up in top of this slope without any purification measures till over a decade ago, the contaminants from waste residue leached by rainwater which flows into pools and farmlands down along this slope and then resulted in severe ecological degradation [2]. Meizhou city enjoys a warm and humid subtropical monsoon climate with abundant sunshine, plenty and concentrated rainfall; the average temperature ranges from 20.6 21.4oC, average annual sunshine hours $1714.6 \sim 2010.5 \mathrm{~h}$, average rainy days is about $150 \mathrm{~d}$, average annual rainfall is $1483.4 \sim 1798.4 \mathrm{~mm}$, with $75 \%$ of which being concentrated in months from April to September, and a frost-free period is $309 \mathrm{~d}$. 


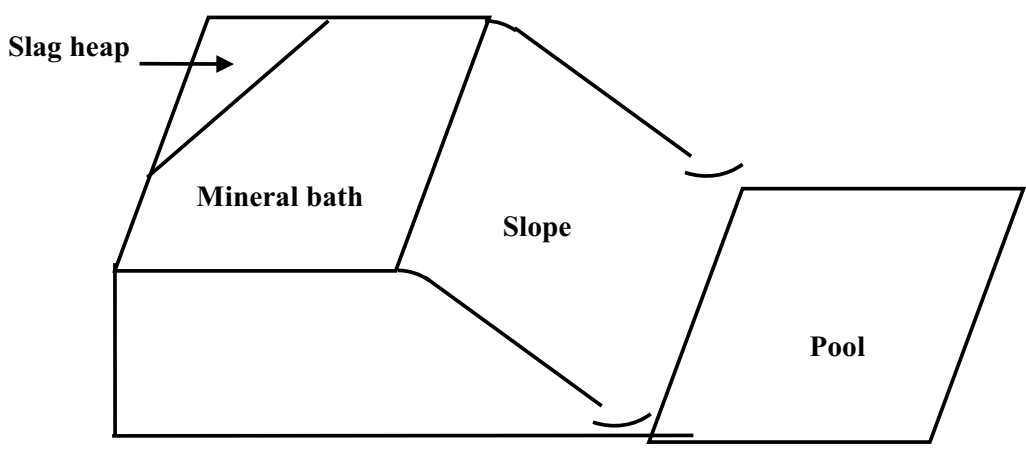

Fig.1. Schematic diagram of Bingcun $\mathrm{Pb}-\mathrm{Zn}$ tailings area

Leaching of heavy metals flows into the water and farmland in the mine area and results in serious pollution. Due to the complexity of the mechanism of heavy metal toxicity to plants and their stability in the soil, the control and treatment of heavy metal pollution has been a hot research task for decades [3-4]. At present, heavy metal pollution in soil and water can be remediated by one or more of the following technologies: isolation, immobilization, toxicity reduction, physical separation or extraction [4-5].

But physical and chemical methods always require a great amount of engineering and investment, and can only repair small contamination area application. Phytoremediation is an effective polluted soil restoration technology developed since the mid19th century, namely heavy metal hyperaccumulator plants are screened, which grown in the polluted soil to absorb and remove heavy metals when they are harvested from the field [6-7]. It is relatively less cost and applicable for remediation of large area of heavy metal polluted soil especially in economic less-developed areas.

Equisetum ramosissimum and Pteris vittata are two dominant plants in Bencun $\mathrm{Pb}-\mathrm{Zn}$ Tailing. On the edge of slope near the pool, the two ferns can grow strong almost as vigorously as in areas far from tailings, but other plants are rarely distributed (Figure 1). In this study, the characteristics of heavy metal absorption and enrichment of Equisetum ramosissimum and Pteris vittata growing close to the edge of a sewage pool in the $\mathrm{Pb}-\mathrm{Zn}$ Mining Tailing were investigated through analysis on heavy metal content in mine soil around the roots, the aboveground and underground parts of the two ferns in order to provide theoretical basis for heavy metal pollution remediation and ecological restoration in $\mathrm{Pb}-\mathrm{Zn}$ tailing area.

\section{Materials and methods}

\subsection{Collection of soil and plant samples}

Samples of the ferns and soil $(0-10 \mathrm{~cm}$ below soil surface) close to edge of the sewage pool were collected in winter of 2014 at interval points in Bencun $\mathrm{Pb}-\mathrm{Zn}$ Tailing, sieved (with $2 \mathrm{~cm}$ holes) and packed on the spot and taken back laboratory for further procedures of analysis.

\subsection{Pretreatment of plant samples}

Plant samples were divided into two parts: aboveground parts and underground parts, rinsed 3 times with tap water, and then cleaned with ultrapure water to avoid interference from heavy metal ions in soil. The samples were dried for 5 min at $105^{\circ} \mathrm{C}$ and at $80^{\circ} \mathrm{C}$ for $8 \mathrm{~h}$, and broken in an organization crusher, then ground into fine powder in mortar. Powder samples were preserved for $2 \mathrm{~h}$ in an oven at $105 \mathrm{oC}$ and used in subsequent experiments described below after being sieved with 200 mesh sieve.

\subsection{Pretreatment of soil samples}

Soil samples were firstly air-dried, from which the stones and animal and plant residues were removed, and milled with agate rods and sieved through $2 \mathrm{~mm}$ nylon sieve, then ground into fine power in agate mortar and followed by sieved with 100 mesh nylon sieve $(0.149 \mathrm{~mm})$, finally preserved for subsequent experiments as described below.

\subsection{Determination of soil $\mathrm{pH}$ value}

$10 \mathrm{~g}$ soil samples after pretreatment were taken into a $50 \mathrm{ml}$ beaker, added $25 \mathrm{ml}$ boiled distilled water, stirred vigorously for $1 \sim 2 \mathrm{~min}$ with a glass rod and let stand for $30 \mathrm{~min}$, then measured by $\mathrm{pH}$ meter.

\subsection{Digestion of plant and soil samples}


Digestion of plant and soil samples was basically carried out as described byYang et al.(2012), but made some subtle changes. Briefly, $0.5 \mathrm{~g}$ of plant and soil powder was placed into a $50 \mathrm{ml}$ ptfe high-pressure digestion tanks (KH-100 ml, Shanghai Yingdi Instrument Equipment Co., LTD.), and wet with 4 drops of double distilled water, then transferred to a ventilation cabinet for an overnight cold digestion after slowly adding $5 \mathrm{ml} \mathrm{HNO}_{3}$ to remove organic matter after soaking for $0.5 \mathrm{~h}$. Followed by addition of $2 \mathrm{ml} \mathrm{H}_{2} \mathrm{O}_{2}$, the digestion tanks were taken into the supporting steel liners. After being covered inner lids and firmly tightened stainless steel sheathes, the tanks with plant samples were transferred to a constant oven and heated for $3 \mathrm{~h}$ after the temperature rose to $120^{\circ} \mathrm{C}$, but those with soil samples were transferred to oven and heated for $9 \mathrm{~h}$ at $160^{\circ} \mathrm{C}$. When all the tanks naturally dropped to room temperature $\left(25 \sim 30^{\circ} \mathrm{C}\right)$ in the oven, they were placed on electric heating plates to dispel $\mathrm{HNO}_{3}$ in the digestion liquid after their lids were carefully opened. Digestion liquid was transferred to $50 \mathrm{ml}$ calibration test tubes for constant volume with $0.5 \% \mathrm{HNO}_{3}$ solution which was then shook, let stand, and used in subsequent tests. For each batch of soil samples, double distilled water was replaced samples in 2 copies of reagent blank test.

\subsection{Determination the heavy metals of plant samples and soil samples}

Heavy metal $(\mathrm{Cr}, \mathrm{Mn}, \mathrm{Ni}, \mathrm{Cu}, \mathrm{Zn}, \mathrm{Cd}, \mathrm{Hg}$ and $\mathrm{Pb}$ ) contents in digested solution of plant and soil samples were determined in parallel using X Series 2 inductively coupled plasma mass spectrometry (ICP-MS, Thermo Fisher).

\subsection{Assessment of heavy metal enrichment capability of ferns and soil heavy metal pollution}

Heavy metal enrichment capability of plants was evaluated by indicators of TF (transfer factor) and EC (enrichment coefficient). TF of heavy metals for plant is the ratio of metal content in above-ground parts to that in underground parts. EC of heavy metals for plant is the ratio of metal content in organs or parts of plant to that in the soil where the plant grows, which reflects the plants' capability to enrich heave metals from its soil or water environment. The larger the enrichment coefficient of a metal is, the easier the element will be enriched. Single factor pollution index and Nemerow pollution index were applied to assess heavy metal pollution, and potential ecological risk index was calculated according to the method proposed by Hakanson [8]. The potential ecological risk level was assessed according to criteria of the second or third grade Environmental Quality Standard in China for Soils (GB 15618-1995) based on soil background values of Guangdong Province [9-11].

The calculation formula of single factor pollution index is $P_{i}=C_{i} / S_{i} . P_{i}$ refers to the single factor pollution index of pollutants in soil; $C_{i}$ refers to the measured content of pollutants in soil; $S_{i}$ to the evaluation standard of pollutant. The formula of Nemerow synthetic pollution index is $P=\left\{\left[\left(C_{i} / S_{i}\right)^{2} \text { max }+\left(C_{i} / S_{i}\right)^{2} \text { ave }\right] / 2\right\}^{1 / 2} \cdot\left(C_{i} / S_{i}\right)_{\text {Max }}$ refers to the maximum of pollution index in soil; $\left(\mathrm{C}_{\mathrm{i}} / \mathrm{S}_{\mathrm{i}}\right)_{\text {Ave }}$ to the average pollution index in soil.

The formula of potential ecological risk index is: $\mathrm{E}_{\mathrm{r}}{ }_{\mathrm{i}}=\mathrm{T}_{\mathrm{r}}{ }^{\mathrm{i}} \times \mathrm{C}_{\mathrm{f}}{ }^{\mathrm{i}}=\mathrm{T}_{\mathrm{r}}{ }^{\mathrm{i}} \times \mathrm{C}_{\mathrm{i}} / \mathrm{S}_{\mathrm{i}} ; \mathrm{RI}=\sum \mathrm{E}_{\mathrm{r}}{ }^{\mathrm{i}}$. $\mathrm{E}_{\mathrm{r}}{ }^{\mathrm{i}}$ refers to the single heavy metal potential ecological risk index; $\mathrm{T}_{r}^{\mathrm{i}}$ refers to heavy metal toxicity coefficient, RI to the potential ecological risk index of a variety of various metals. The heavy pollution level and potential ecological risk of heavy metal pollution were determined according to the classification standard of heavy metal pollution level [12-13].

\subsection{Data analysis}

All data were proceeded and analyzed with Excel2003 and SPSS17, and multiple comparison of means was carried out by Duncan's $(\mathrm{P}<0.05)$ multiple range tests.

\section{Results}

\subsection{Soil pH}

The $\mathrm{pH}$ value of soil was 7.78, which revealed a weak alkaline. When evaluating the pollution level of heavy metal in soil, the numerical criteria should refer to the range of $\mathrm{pH}$ value above 7.5 in the second grade SSEQS (State Soil Environmental Quality Standard) in China or greater than 6.5 in the third grade SSEQS. Guo et al. found that in Guangdong Province, the spatial distribution pattern of soil $\mathrm{pH}$ in the Province had less change (mainly acidic), except that in Pearl River Delta and part of Qingyuan and Shaoguan (weak alkaline) City in the past over 30 years and industrialization and mining increased the soil $\mathrm{pH}$ in some areas[14].

\subsection{Heavy metal content of soil}

The data showed that the heavy metal content in soil was in descending order of $\mathrm{Pb}, \mathrm{Mn}, \mathrm{Zn}, \mathrm{Cu}, \mathrm{Cd}, \mathrm{Cr}, \mathrm{Ni}, \mathrm{Hg}$. $\mathrm{Pb}$ content in soil reached the maximum (13332.94 mg.kg-1), but Hg content was the minimum (only $4.12 \mathrm{mg} . \mathrm{kg}-1$ ). The contents of $\mathrm{Pb}, \mathrm{Zn}, \mathrm{Cd}$ and $\mathrm{Hg}$ were far above the third grade SSEQS, and were 26.67, 10.81, 39.62, and 2.75 times more than the third grade SSEQS, respectively. Cu content was above the second grade SSEQS, but $\mathrm{Cr}$ and Ni content 
did not exceed national standard. In addition to $\mathrm{Cr}$, the content of other heavy metals exceeded the background value in soil of Guangdong Province, that of $\mathrm{Cd}$ was even 707.50 times more than the background value, it is reported that the medium standard of Mn content in soil was $170 \sim 1200 \mathrm{mg} \mathrm{kg}-1$, so the Mn content in the region exceeded the medium standard; the Ni content didn't exceed the national standard, but also 1.32 times more than the soil background value in Guangdong province (Table 1).

Table 1. The content of heavy metals in soil.

\begin{tabular}{|c|c|c|c|c|c|c|c|c|}
\hline Heavy metal & $\mathrm{Cr}$ & $\mathrm{Mn}$ & $\mathrm{Ni}$ & $\mathrm{Cu}$ & $\mathrm{Zn}$ & $\mathrm{Cd}$ & $\mathrm{Hg}$ & $\mathrm{Pb}$ \\
\hline Content $\left(\mathrm{mg} \mathrm{kg}^{-1}\right)$ & 20.32 & 12575.67 & 19.05 & 272.92 & 5404.75 & 39.62 & 4.12 & 13332.94 \\
\hline
\end{tabular}

\subsection{Evaluation on the single factor and synthetic pollution index of heavy metals}

According to the second grade SSEQS (but Mn content has not been set in the SSEQS), the single factor pollution index of $\mathrm{Cr}$ and $\mathrm{Ni}$ belonged to the clean degree, other five metals all had reached the pollution level. The decreasing order of single factor pollution index was $\mathrm{Cd}, \mathrm{Pb}, \mathrm{Zn}, \mathrm{Hg}$ and $\mathrm{Cu}$, the single factor pollution index of $\mathrm{Cd}, \mathrm{Pb}, \mathrm{Zn}, \mathrm{Hg}, \mathrm{Mn}$ and $\mathrm{Cu}$ reached the heavy level, but that of Ni reached the light degree (Table 2). Both the synthetic pollution index of heavy metals calculated on the basis of the second SSEQS and the soil background value in Guangdong Province reached the heavy pollution level.

Table 2.The index and grade of soil heavy metal pollution.

\begin{tabular}{|c|c|c|c|c|c|c|c|c|c|}
\hline Heavy metal & $\mathrm{P}_{\mathrm{Cr}}$ & $\mathrm{P}_{\mathrm{Mn}}$ & $\mathrm{P}_{\mathrm{Ni}}$ & $\mathrm{P}_{\mathrm{Cu}}$ & $\mathrm{P}_{\mathrm{Zn}}$ & $\mathrm{P}_{\mathrm{Cd}}$ & $\mathrm{P}_{\mathrm{Hg}}$ & $\mathrm{P}_{\mathrm{Pb}}$ & $\mathrm{P}_{\text {综 }}$ \\
\hline $\mathrm{S}_{1}$ & $0.08 \mathrm{C}$ & $\mathrm{NA}$ & $0.32 \mathrm{C}$ & $1.36 \mathrm{~L}$ & $18.02 \mathrm{H}$ & $66.03 \mathrm{H}$ & $4.12 \mathrm{H}$ & $38.09 \mathrm{H}$ & $48.45 \mathrm{H}$ \\
\hline $\mathrm{S}_{2}$ & $0.40 \mathrm{C}$ & $45.07 \mathrm{H}$ & $1.32 \mathrm{~L}$ & $16.05 \mathrm{H}$ & $114.27 \mathrm{H}$ & $707.50 \mathrm{H}$ & $52.82 \mathrm{H}$ & $370.36 \mathrm{H}$ & $513.46 \mathrm{H}$ \\
\hline
\end{tabular}

Note: S means security, W means alert; C means clean; L means light pollution; M means moderate pollution; $\mathrm{H}$ means heavy pollution. $\mathrm{S}_{1}$ was calculated based on the second grade State Soil Environmental Quality Standard, $\mathrm{S}_{2}$ was calculated based on the soil background value in Guangdong Province, the second grade State Soil Environmental Quality Standard, NA means the data cannot be calculated because Mn content has not been set in the State Soil Environmental Quality Standard, the same as below.

\subsection{Evaluation of potential ecological risk of heavy metals in soil index}

Based on the second grade SSEQS, the descending order of ecological risk index was $\mathrm{Cd}, \mathrm{Pb}, \mathrm{Hg}, \mathrm{Zn}, \mathrm{Cu}, \mathrm{Ni}, \mathrm{Cr}$, the potential ecological risk index for $\mathrm{Cd}$ was the highest and reached very strong level, those of $\mathrm{Pb}$ and $\mathrm{Hg}$ both reached strong degree, but those of $\mathrm{Zn}, \mathrm{Cu}, \mathrm{Ni}$ and $\mathrm{Cr}$ was lower and reached minor level, and even that of $\mathrm{Cr}$ was below 1 and had hardly any hazard. Based on the soil background value in Guangdong Province, the decreasing order was $\mathrm{Cd}, \mathrm{Hg}$, $\mathrm{Pb}, \mathrm{Zn}, \mathrm{Cu}, \mathrm{Ni}$ and $\mathrm{Cr}$, the potential ecological risk index of $\mathrm{Cd}, \mathrm{Hg}$ and $\mathrm{Pb}$ reached extremely high degree, those of $\mathrm{Zn}$ and $\mathrm{Cu}$ reached high degree, but those of $\mathrm{Ni}$ and $\mathrm{Cr}$ was relatively low and reached slight degree (Table 3 ).

Table 3. The index and grade of potential ecological risks of soil heavy metal pollution.

\begin{tabular}{|c|c|c|c|c|c|c|c|c|c|}
\hline $\begin{array}{c}\text { Heavy } \\
\text { metal }\end{array}$ & $\mathrm{E}_{\mathrm{r}}^{\mathrm{Cr}}$ & $\mathrm{E}_{\mathrm{r}}^{\mathrm{Mn}}$ & $\mathrm{E}_{\mathrm{r}}^{\mathrm{Ni}}$ & $\mathrm{E}_{\mathrm{r}}^{\mathrm{Cu}}$ & $\mathrm{E}_{\mathrm{r}}^{\mathrm{Zn}}$ & $\mathrm{E}_{\mathrm{r}}^{\mathrm{Cd}}$ & $\mathrm{E}_{\mathrm{r}}^{\mathrm{Hg}}$ & $\mathrm{E}_{\mathrm{r}}^{\mathrm{Pb}}$ & $\mathrm{RI}$ \\
\hline $\mathrm{S}_{1}$ & $0.16 \mathrm{~A}$ & $\mathrm{NA}$ & $1.59 \mathrm{~A}$ & $6.82 \mathrm{~A}$ & $18.02 \mathrm{~A}$ & $1981.00 \mathrm{E}$ & $164.80 \mathrm{D}$ & $190.47 \mathrm{D}$ & $2362.86 \mathrm{D}$ \\
\hline $\mathrm{S}_{2}$ & $0.80 \mathrm{~A}$ & $\mathrm{NA}$ & $6.61 \mathrm{~A}$ & $80.27 \mathrm{C}$ & $114.27 \mathrm{C}$ & $21225.00 \mathrm{E}$ & $2112.82 \mathrm{E}$ & $1851.80 \mathrm{E}$ & $25391.57 \mathrm{D}$ \\
\hline
\end{tabular}

Note: A. Slight; B. Moderate; C. Strong; D. Very strong; E.Strmely strong

\subsection{Heavy metal content and transfer coefficients of two ferns}

Enrichment pattern of heavy metals including $\mathrm{Cr}, \mathrm{Mn}, \mathrm{Ni}, \mathrm{Cu}, \mathrm{Zn}, \mathrm{Cd}, \mathrm{Hg}$ and $\mathrm{Pb}$ in Equisetum ramosissimum was different from that in Pteris vittata. For both the ferns, heavy metal contents of the aboveground parts were below that of underground parts, namely the heavy metals were mainly concentrated in the underground parts. For Equisetum ramosissimum, the decreasing order of heavy metal content in aboveground parts was $\mathrm{Zn}, \mathrm{Mn}, \mathrm{Pb}, \mathrm{Cu}, \mathrm{Ni}, \mathrm{Cd}, \mathrm{Cr}, \mathrm{Hg}$, and that in underground parts was $\mathrm{Zn}, \mathrm{Mn}, \mathrm{Pb}, \mathrm{Cu}, \mathrm{Cd}, \mathrm{Ni}, \mathrm{Cr}, \mathrm{Hg}$. For Pteris vittata, the decreasing order of heavy metal content was $\mathrm{Zn}, \mathrm{Mn}, \mathrm{Pb}, \mathrm{Cu}, \mathrm{Ni}, \mathrm{Cr}, \mathrm{Cd}, \mathrm{Hg}$ in aboveground parts, while that was $\mathrm{Zn}, \mathrm{Mn}, \mathrm{Pb}, \mathrm{Cu}, \mathrm{Ni}, \mathrm{Cd}, \mathrm{Cr}, \mathrm{Hg}$ in underground parts, i.e, besides that $\mathrm{Cd}$ and $\mathrm{Cr}$ were in reverse order, the other 6 metals are in the same order.

Except that the transfer coefficient of $\mathrm{Hg}$ in Equisetum ramosissimum was above 1, all the other transfer coefficients of heavy metals in both Equisetum ramosissimum and Pteris vittata were below 1. As for the same heavy metal, the transfer coefficients of Equisetum ramosissimum were above those of Pteris vittata (Table 4). 
Table 4. Heavy metal content $\left(\mathrm{mg} \cdot \mathrm{kg}^{-1}\right)$ of above and under ground parts and transfer coefficients.

\begin{tabular}{|c|c|c|c|c|c|c|}
\hline Species & \multicolumn{3}{|c|}{ Equisetum ramosissimum } & \multicolumn{3}{c|}{ Pteris vittata } \\
\hline Part & Above-ground & underground & TF & Above-ground & underground & TF \\
\hline $\mathrm{Cr}$ & 1.82 & 4.63 & 0.39 & 1.40 & 6.10 & 0.23 \\
\hline $\mathrm{Mn}$ & 427.16 & 1487.33 & 0.29 & 56.78 & 1233.80 & 0.05 \\
\hline $\mathrm{Ni}$ & 9.81 & 12.26 & 0.80 & 4.06 & 20.35 & 0.20 \\
\hline $\mathrm{Cu}$ & 52.70 & 110.24 & 0.48 & 9.00 & 92.18 & 0.10 \\
\hline $\mathrm{Zn}$ & 819.41 & 2734.91 & 0.30 & 176.55 & 1460.52 & 0.12 \\
\hline $\mathrm{Cd}$ & 6.88 & 18.12 & 0.38 & 0.88 & 11.76 & 0.07 \\
\hline $\mathrm{Hg}$ & 0.17 & 0.11 & 1.55 & 0.11 & 0.29 & 0.38 \\
\hline $\mathrm{Pb}$ & 300.37 & 697.97 & 0.43 & 36.23 & 783.08 & 0.05 \\
\hline
\end{tabular}

\subsection{Enrichment coefficient of above and underground parts for two ferns}

Table 5. Heavy metal enrichment coefficients of above and under round parts for two ferns.

\begin{tabular}{|c|c|c|c|c|}
\hline Species & \multicolumn{2}{|c|}{ Equisetum ramosissimum } & \multicolumn{2}{c|}{ Pteris vittata } \\
\hline Part & Above-ground parts & Underground parts & Above-ground parts & Underground parts \\
\hline $\mathrm{Cr}$ & 0.09 & 0.25 & 0.07 & 0.30 \\
\hline $\mathrm{Mn}$ & 0.03 & 0.13 & 0.004 & 0.10 \\
\hline $\mathrm{Ni}$ & 0.51 & 0.73 & 0.21 & 1.07 \\
\hline $\mathrm{Cu}$ & 0.19 & 0.35 & 0.03 & 0.34 \\
\hline $\mathrm{Zn}$ & 0.15 & 0.33 & 0.03 & 0.27 \\
\hline $\mathrm{Cd}$ & 0.17 & 0.26 & 0.02 & 0.30 \\
\hline $\mathrm{Hg}$ & 0.04 & 0.03 & 0.03 & 0.07 \\
\hline $\mathrm{Pb}$ & 0.02 & 0.05 & 0.0027 & 0.06 \\
\hline
\end{tabular}

Except that the enrichment coefficient of $\mathrm{Ni}$ in Pteris vittata was above 1, the enrichment coefficients of all metals in both ferns were below 1. In Equisetum ramosissimum, the descending order of 8 heavy metals in the aboveground parts were $\mathrm{Ni}, \mathrm{Cu}, \mathrm{Cd}, \mathrm{Zn}, \mathrm{Cr}, \mathrm{Hg}, \mathrm{Mn}, \mathrm{Pb}$, and that in underground parts were $\mathrm{Ni}, \mathrm{Cu}, \mathrm{Zn}, \mathrm{Cd}, \mathrm{Cr}, \mathrm{Mn}, \mathrm{Pb}$ and $\mathrm{Hg}$. $\mathrm{In}$ Pteris vittata, the order of enrichment coefficients in aboveground parts were $\mathrm{Ni}>\mathrm{Cr}>\mathrm{Cu}=\mathrm{Zn}>\mathrm{Cr}>\mathrm{Pb}$, and that in underground parts were $\mathrm{Ni}>\mathrm{Cu}>\mathrm{Cr}=\mathrm{Cd}>\mathrm{Zn}>\mathrm{Mn}>\mathrm{Hg}>\mathrm{Pb}$. The ECs of both ferns were low, and that in aboveground parts were below in the underground parts (Table 5).

\section{Discussion}

\subsection{Evaluation of heavy metal content and pollution in soil}

Soils in most regions of Guangdong Province is acid[10], but the soil in Bencun Pb- $\mathrm{Zn}$ Tailing was weak alkaline, which may be due to large volume $\mathrm{CaCO}_{3}$ application during the mine construction and operation in recent years. The soil heavy metal pollution in this tailing is undoubtedly a composite pollution, the content of $\mathrm{Pb}, \mathrm{Zn}, \mathrm{Cu}, \mathrm{Cd}$ and $\mathrm{Hg}$ in the soil was all above SSEQS and the soil background value in Guangdong Province, the Mn content was 45.07 times above the soil background value in Guangdong Province and also above Mn moderate standard. Liu et al. found the content of $\mathrm{Pb}, \mathrm{Zn}, \mathrm{Cd}$ and $\mathrm{Cu}$ in soils on a ladder slope in Bencun $\mathrm{Pb}-\mathrm{Zn}$ Tailing[6], the results were shown that the content of 4 heavy metals were below that in soils close to edge of the sewage pool in this study, which suggested that the soil pollution of heavy metals close to pool, including $\mathrm{Pb}, \mathrm{Zn}, \mathrm{Cd}, \mathrm{Cu}$, was more serious than other areas in the tailing, because long term rain erosion caused accumulation of heavy metals in pools surrounding the tailing. Based on the analysis of soil heavy metal pollution index and pollution levels, it is not difficult to find that the main factors in the soil heavy metal pollution were $\mathrm{Cd}, \mathrm{Pb}, \mathrm{Zn}$ and $\mathrm{Hg}$ which had reached heavy pollution level, so the accumulation of these 4 heavy metals was key causes for the soil pollution. Soil RI of heavy metals is high, indicating the soil has high potential ecological risk of heavy metal pollution. In Bencun $\mathrm{Pb}-\mathrm{Zn}$ Tailing, $\mathrm{Cd}, \mathrm{Hg}$ and $\mathrm{Pb}$ were the main factors of the potential ecological risk, followed by $\mathrm{Cu}, \mathrm{Zn}$, so the soil in this tailing does not meet the requirements for growing crops. These results were consistent with studies made by Chu \& Luo [15] that in Qixiashan Pb-Zn Tailing, the main pollution 
elements were $\mathrm{Pb}, \mathrm{As}, \mathrm{Cd}$ and $\mathrm{Zn}$, as well as a mild $\mathrm{Cu}$ pollution in some soils. In Changhua $\mathrm{Pb}-\mathrm{Zn}$ Tailing, the heavy metal pollution, including $\mathrm{Cd}, \mathrm{Cu}, \mathrm{Pb}$ and $\mathrm{Zn}$, reached very high pollution levels [16]. As described by Li et al. [17], in Shuikoushan $\mathrm{Pb}-\mathrm{Zn}$ Tailings, $\mathrm{Cd}$ pollution was the most serious, and there also was a serious pollution of $\mathrm{Cd}, \mathrm{Pb}, \mathrm{Hg}$ and mild compound pollution of $\mathrm{Zn}$ and $\mathrm{As}$. Therefore, in $\mathrm{Pb}-\mathrm{Zn}$ tailings, there usually exists a serious composite pollution of $\mathrm{Cd}, \mathrm{Pb}, \mathrm{Zn}$ and $\mathrm{Cu}$, which also occurred in the present study. In addition, $\mathrm{Hg}$ pollution cannot be ignored in Bencun $\mathrm{Pb}-\mathrm{Zn}$ Tailing.

\subsection{The characteristics of heavy metal absorption and enrichment of two ferns}

The definition of heavy metal hyperaccumulator widely used at present is the reference values of heavy metals in plants proposed by Baker and Brooks [18], the critical content of $\mathrm{Zn}$ is $10000 \mathrm{mg} \cdot \mathrm{kg}^{-1}, \mathrm{Cd} 100 \mathrm{mg} \cdot \mathrm{kg}^{-1}, \mathrm{Hg} 10 \mathrm{mg} \cdot \mathrm{kg}^{-1}, \mathrm{~Pb}, \mathrm{Cu}$, $\mathrm{Ni}$, Co $1000 \mathrm{mg} \cdot \mathrm{kg}^{-1}$, and both EC (enrichment coefficient) and TC (transport coefficient) of these plant should be above 1 .

In the present study, $\mathrm{Pb}$ or $\mathrm{Zn}$ content of underground parts in Equisetum ramosissimum and Pteris vittata are very high and above the normal content range in plants $\left(0.1 \sim 4.17 \mathrm{mg} \cdot \mathrm{kg}^{-1}\right.$ for $\left.\mathrm{Pb}, 1.0 \sim 160 \mathrm{mg} \cdot \mathrm{kg}^{-1} \mathrm{for} \mathrm{Zn}\right)[7]$, but the content of two ferns were far below the critical content standard of hyperaccumulators. When the heavy metal pollution in soil is heavy, the plant growth and crop yield may decrease. It was reported that when the $\mathrm{Zn}$ concentration reached $140 \sim 310 \mathrm{mg} \cdot \mathrm{kg}^{-1}$ in soil [3], it could inhibit the growth and development of barley, rye grass, clover, buckwheat and other plants, but Equisetum ramosissimum and Pteris vittata could grow in Bencun $\mathrm{Pb}-\mathrm{Zn}$ Tailing, and the appearance and growth of these individuals distributing in the tailing were almost the same as those distributing in the non-polluted areas. But the heavy metal content and TC were below the critical standards of hyperaccumulator, for example, the $\mathrm{Pb}$ content of above ground parts in Pteris vittata was only $36.23 \mathrm{mg} \cdot \mathrm{kg}^{-1}$, the TC was only 0.05 , so the two ferns were not typical hyperaccumulators.

$\mathrm{Cd}$ content in plants is usually below $3.00 \mathrm{mg} \cdot \mathrm{kg}^{-1}$, but that in those growing in Cd-enriched soil may be above $20.00 \mathrm{mg} \cdot \mathrm{kg}^{-1}$, even if growing in Cd-contaminated soils, it is rarely above $100.00 \mathrm{mg} \cdot \mathrm{kg}^{-1}[5]$. In this study, the Cd content of Equisetum ramosissimum and Pteris vittata was above $3.00 \mathrm{mg} . \mathrm{kg}^{-1}$, suggesting the two ferns had relatively strong $\mathrm{Cd}$ tolerance, even though $\mathrm{Cd}$ content did not exceed the threshold for hyperaccumulator.

Mn content in plants is usually in the range of $1.0 \sim 700.0 \mathrm{mg} \cdot \mathrm{kg}^{-1}[7]$, but that of Equisetum ramosissimum and Pteris vittata in this study was above the normal value range. The EC was too low and below 1 . So the two ferns are likely to have strong adaptability to high $\mathrm{Mn}$-enriched soil and can be used as a pioneer in ecological restoration of $\mathrm{Pb}-\mathrm{Zn}$ tailings.

$\mathrm{Cu}$ content of Equisetum ramosissimum was above that of general plants whose $\mathrm{Cu}$ content is usually $0.4 \sim 45.8$ mg. $\mathrm{kg}^{-1}[7]$ and mainly accumulated in underground parts. TC and EC were both below 1, but it has been reported in other researches that $\mathrm{EC}$ of Equisetum ramosissimum was above 1, indicating Equisetum ramosissimum has some $\mathrm{Cu}$ enrichment ability and can be regarded as a phytoremediation plant in Cu-polluted soils[19].

The normal Ni content for most plants is $0.05 \sim 5.00 \mathrm{mg} \cdot \mathrm{kg}^{-1}$. When Ni content in the dry matter of plants reaches $0.01 \sim 0.15 \mathrm{mg} . \mathrm{kg}^{-1}$, leaves appear on urea toxic symptoms and had tip necrosis [20]. In this study, except in the above ground parts of Pteris vittata, Ni content of other parts in two ferns was above $5.00 \mathrm{mg} . \mathrm{kg}^{-1}$, so the two ferns can be regarded as ideal Ni pollution tolerant plants.

$\mathrm{Hg}$ content of Equisetum ramosissimum and Pteris vittata was far above that reported in other plants $(0.010 \sim 0.050$ mg. $\mathrm{kg}^{-1}$ ) [21], which confirmed the two ferns were subject to a certain level of $\mathrm{Hg}$ pollution, but they were still not typical $\mathrm{Hg}$ hyperaccumulators because $\mathrm{Hg}$ content of the two ferns was below the critical content value $\left(10 \mathrm{mg}^{\mathrm{kg}} \mathrm{kg}^{-1}\right)$ and EC was below 0.1. Han (2012) carried out a cultivation experiment of Pteris vittata in $10 \mathrm{mg} \cdot \mathrm{kg}^{-1} \mathrm{Hg}_{\mathrm{solution}}$ and found its TC and EC were $0.38 \sim 0.71$ and $0.01 \sim 0.06$ respectively [22], these results were similar to the results in this study. The Cr content in plants are usually $0 \sim 8.4 \mathrm{mg} \cdot \mathrm{kg}^{-1}[7]$, that of these two ferns were also within the range.

In conclusion, the soil in Bencun $\mathrm{Pb}-\mathrm{Zn}$ Tailing was severely polluted by heavy metals, especially $\mathrm{Cd}, \mathrm{Cu}$ and $\mathrm{Mn}$. The potential ecological risk of heavy metals was assessed to be very strong based on soil background values of Guangdong Province and at high risk according to criteria of the second grade SSEQS, and $\mathrm{Cd}, \mathrm{Hg}, \mathrm{Pb}$ were the main factors leading to potential ecological risk. The content of 8 heavy metals in Equisetum ramosissimum and Pteris vittata did not reach critical content of hyperaccumulator, so neither of them was typical hyperaccumulator, but both had a certain tolerance to the combined pollution of $\mathrm{Pb}, \mathrm{Zn}, \mathrm{Mn}, \mathrm{Cu}, \mathrm{Cd}, \mathrm{Hg}$ and $\mathrm{Ni}$. The underground parts of two ferns had a relatively strong enrichment, the EC of $\mathrm{Ni}$ in underground parts of Equisetum ramosissimum was near 1, and that in Pteris vittata was over 1 , so the two ferns could be utilized as Ni potential enrichment plants. The transfer ability of 8 heavy metals by the two ferns was not strong, except for $\mathrm{Hg}$ by Equisetum ramosissimum, the TC of other metals by Equisetum ramosissimum and that of the 8 heavy metals by Pteris vittata were below 1 . The heavy metal pollution in ground soil could increase after the ferns withered, but the heavy metals could be fixed in the soil and could not unlimitedly migrate and diffuse, water heavy metal pollution was then reduced. The two ferns can grow vigorously in the tailing indicating they had strong adaptability to the tailing habitat, so they can be used as pioneers in ecological restoration of $\mathrm{Pb}-\mathrm{Zn}$ tailings. 


\section{Acknowledgements}

This work was financially supported by Key Project of Science and Technology Innovation of Colleges and Universities in Guangdong Province (cxzd1132); Guangdong Province Natural Science Foundation Project (815140150100003) and Special Funds of Talent Introduction of Colleges and Universities in Guangdong Province.

\section{References}

1. Chinese Environmental Protection Administration. State soil environmental quality standard. Beijing: China Standard Press (1997).

2. Q.H.Yang, H.N. Liu, Q.H. Li, J.Q. Li and C. Q. Tu. Study on the microbial acitivity of rhizosphere soil for three dominant plants in $\mathrm{Pb}-\mathrm{Zn}$ wasteland in Eastern Guandong Province. Chinese Agricultural Science Bulletin, Vol. 28(2012),p.56-64.

3. J.H. Yang. Soil Pollution and Control. Science Press, Beijing (1995).

4. C.A. Evanko and D.A. Dzombak: Remediation of metals-contaminated soils and groundwater, in:Technology Evaluation Report, TE 97-0-1, Ground-water Remediation Technologies Center, edited by P.A. Pittsburgh (1997).

5. S.R. Tang. Phytoremediation of contaminated soils. Science Press, Beijing (2006).

6. H.N.Liu, Q.H.Yang, H.S.Yang, J.Q.Li and D.L.Liu. Characteristics of heavy metals Pb-Zn mine absorption and accumulation of for three dominant plants in tailings eastern Guangdong. Guihaia,Vol.32(2012), p.743-749.

7. C.Lu, Y.H.Wang and J.W.Yang. Soil heavy metal pollution and dominant plants selection in Pb-Zn mining areas of Guangxi. Chinese Journal of Soil Science, Vol.41(2010),p. 1471-1474.

8. L.Hakanson. An ecology risk index for squatic pollution control: A sedimentological approach.Water Research, Vol.14 (1980), p. 975-1001.

9. S.D.Wu. The atlas of soil environmental background value in the People's Republic of China. China Environmental Science Press (1994).

10. L.F. Xu and T.H. Liu. The zonal differentiation of soil environmental background values and critical contents in Guangdong. Journal of South China Agricultural University, Vol.17(1996), p. 58-62.

11. S.W.Chai, Y.M.Wen, Y.Zhang and J.F.Zhao. Application of Index of Geoaccumulation ( Igeo) to Pollution Evaluation of Heavy Metals in Soil. Journal of Tongji University (Natural Science), Vol. 34 (2006), p. 1657-1661.

12. Q. Li, Y.F. Han, D.S. Xu and Y. Gao. Enrichment characteristics and contaminant assessment of heavy metals in three food crops around the gangue dumps. Journal of safety and Environment, Vol.14(2014),p.321-326.

13. Y.Q.Luo, Y.P.Chen, L.Tao, Y.Q.Li and X.M.Wang. Investigation and evaluation on heavy metals pollution in farmland soil in Lanzhou City. Journal of Gansu Agricultural University, Vol.45(2011),p. 98-104.

14. Z.X.Guo, J.Wang, M.Chai, Z.P.Chen, Z.S.Zhan, W.P.Zheng and X.G.Wei. Spatiotemporal variation of soil Ph in Guangdong Province of China in past 30 years. Chinese Journal of Applied Ecology, Vol.22(2011), p.425-430.

15. B.B. Chu and L.Q. Luo. Evaluation of heavy metal pollution in soils from Nanjing Qixiashan Lead-Zinc Mines. Rock and Mineral Analysis,Vol.29(2010),p. 5-8,13.

16. S.F.Lu. Soil heavy metal elements content characteristics and pollution evaluation in Changhua lead-zinc mine tailings wasteland of Hainan. Hainan Normal University, Hainan, China (2012).

17. G. Li, F.P. Tong and Z.H. Liu. Analysis on pollution of heavy metal in Shuikoushan Pb-Zn mining and smelting area in Hengyang. Journal of Central South University of Forestry and Technology, Vol.32(2012),p.105-110.

18. A.J.M. Baker and R.R.Brooks. Terrestrial higher plants which hyperaccumulate metallic elements-a review of their distribution, ecology and phytochemistry. Biorecovery, Vol.1(1989), p. 81-126.

19. Y.Li and L.Chu. The uptake and accumulation of $\mathrm{Cu}$ in Hippochaete ramosissimum. Acta Ecologica Sinica, Vol.28 (2008), p.1565-1573.

20. X.X.Long and X.E. Yang. Nickel nutrition of plants. Chinese Journal of Soil Science, Vol. 31 (2000), p.39-42.

21. D.M. Zheng, Q.C. Wang and Z.S. Zhang. Transfer of mercury in soil-plant system of Wuli river, Huludao City. China Enviromental Science, Vol.27(2007),p. 676-680.

22. S.H. Han. A Comparative study on Removal Performance of $\mathrm{Hg}$ and $\mathrm{Cd}$ in Agriculture Soils for Several Plants. Donghua University, Shanghai (2012). 